\title{
OFFER: A Broker-Centered Object Framework For Electronic Requisitioning
}

\author{
Martin Bichler, Carrie Beam, Arie Segev \\ Fisher Center For Management \& Information Technology \\ Walter A. Haas School of Business, University of California, Berkeley \\ Berkeley, CA 94720-1930, USA \\ \{bichler, beam, segev\}@haas.berkeley.edu
}

\begin{abstract}
Procurement is one of the most important business functions. Especially in highly mechanized mass-production industries, the proportion of income dollars spent on purchasing is relatively high. Distributed object systems provide a key to building interoperable applications that can execute on a range of platforms. We propose a CORBA-based object framework called OFFER, focused on electronic procurement and business-to-business commerce. This paper discusses the design and implementation of the electronic broker in OFFER. Key functionality of the broker is the ability to search in underlying electronic catalogs and the ability to use auction mechanisms to buy or sell goods.
\end{abstract}

\section{Introduction}

\subsection{Motivation}

Procurement is one of the most important business functions, and it affects project expenses and quality of the final product. The proportion of income dollars spent on procuring goods and services ranges between $35 \%$ in industries like printing and publishing to $90 \%$ in industries like petroleum [32]. Information technologies like the Web have the potential to radically change the way procurement is done, reducing the cost of procurement and making the entire supply chain more efficient.

Currently, much automated electronic procurement (e-procurement) is done between pairs of companies using technology such as EDI running over proprietary, closed systems. It is mainly production procurement between companies, which have long-standing relationships with each other. Electronic commerce and the Internet introduce a new marketspace with new methods of procurement. This new electronic marketspace contains a melee of smaller companies, each one relatively unknown and together offering a bewildering array of products. This radical change in the electronic marketspace will lead to a radical change in automated e-procurement. Specifically, it will make an electronic broker (e-broker) very useful in certain procurement domains. 
This paper describes an electronic broker built on distributed object technology. The e-broker is part of a larger project developing an object framework for procurement and business-to-business commerce, called OFFER (Object Framework For Electronic Requisitioning). The e-broker in OFFER assists the user in two main ways. First, it helps search in e-catalogs of suppliers; second, it provides auction mechanisms to support price negotiation between buyers and sellers. The components of the framework are implemented in Java and use OMG's CORBA as a distribution infrastructure. We discuss general services of electronic brokers, the implementation in the OFFER framework, and its relationship to OMG's Trading Object Service.

\subsection{Definitions}

Procurement includes all activities involved in obtaining material, transporting it and moving it towards the production process. Positioned between a company's internal customers who need material to fulfill their tasks, and external suppliers, who provide goods and services, the procurement process has to meet multiple objectives simultaneously [24]. Electronic procurement, or electronic tendering of goods and services, is typically practiced by large companies or public authorities, which are seeking additional suppliers and trying to reduce the cost of procurement. It can use either proprietary business-to-business communication lines or, more recently, the Internet. It can be enhanced by electronic negotiation, contracting and ultimately collaborative specification work. Its main benefit is cost reduction, both from lowered transaction processing costs and from the discovery of better offers than were previously found [29]. Initially, most electronic procurement technology merely "paved the cowpaths", using information technology to more efficiently carry out the exact same tasks which were performed manually before. However, electronic procurement is beginning to allow complete re-engineering of the procurement function.

In non-brokered procurement, customers contact suppliers directly, searching for offers and/or conducting one-to-one negotiations. Non-brokered procurement often happens in very small markets, transparent markets, or in markets with monopoly/monopsony structures. A broker is a party, which mediates between buyers and sellers in a marketplace; brokers play an integral part in some procurement transactions. Brokers typically provide services that may include searching for a suitable business partner, negotiating the terms of the deal, providing letters of credit and/or banking/payment services, and ensuring delivery of goods. Brokers are often useful when a marketspace has a large number of buyers and sellers, when search costs are relatively high, or when trust services are necessary.

Current electronic commerce applications, such as those on the World Wide Web, primarily support information collection. There is little or no support for brokerage. However, sophisticated mediators can make the exchange of information between consumers and providers of services cheaper and better. Electronic brokers aim to find the best conditions for their clients (consumers and providers) and they help to overcome the limitations of direct negotiations between customers and suppliers. 


\section{Electronic Procurement Systems}

This section covers electronic procurement systems, and highlights some areas where an electronic broker can be useful: search functionality and negotiation functionality. It also provides a review of distributed object technology in electronic commerce.

\section{1 (R)Evolution of Electronic Procurement Systems}

The past few years have seen several major information technologies come together to produce viable electronic commerce systems. Currently, electronic procurement is mainly supported by EDI and electronic catalogs. EDI has been in use for over 20 years, mostly running on proprietary networks between two businesses [26]. A newer rising technology, made possible by the Internet and WWW, is the electronic catalog. There is no standard definition for the electronic catalog, and the functionality is rapidly evolving, but at a minimum an electronic catalog should support listings of products and/or services, price information and transactions [25]. Electronic catalogs are especially adept at using database and WWW technology to provide sophisticated search and retrieval functionality. In fact, there is already a wide range of packaged software for electronic catalogs available [1]. To use the framework of Schmid [21], for the most part these systems support the information phase of a market transaction well. They support the negotiation phase poorly, and support the payment/settlement phase partially.

The latest developments in electronic procurement technology show an increasing number of systems trying to support all phases of a market transaction. Vendors like Actra, CommerceOne, Elcom or Pandesic build systems which support the whole spectrum of tasks from searching and ordering to shipment and payment. Nearly all of them use well established techniques like the World Wide Web, EDI or e-mail to conduct the purchase. In May 1997 the Internet Purchasing Roundtable tried to standardize this fast evolving area and released OBI 1.0 [14], a standard for eprocurement on the Internet. OBI (Open Buying on the Internet) focuses on frequent or repetitive purchases (typically commodity goods or MRO supplies) with a small number of selling organizations. OBI is based on widely adopted standards like SSL, EDI, SET or HTML. It supports a so-called "neural network model" of business-tobusiness electronic commerce, in which many buyers are connected to many sellers without the use of brokers.

\subsection{Electronic Brokers - The missing Link in E-Procurement}

The systems in Section 2.1 provide no explicit support of an electronic broker. However, in Section 1.2 we identified several scenarios in which an e-broker can provide very valuable services. This section highlights two functions an electronic broker can provide for an electronic market transaction: the search and the negotiation function. It provides a brief overview of current technology in each of the two areas. 


\subsection{Broker-assisted Search and Negotiation Support}

For standardized MRO (Maintenance, Repair and Operations) items, there is often simply too much data for each requisitioner to complete a full search economically. Here a broker can search the databases of underlying electronic catalogs and return the results to the requisitioner [22]. Andersen Consulting's Bargainfinder (http://bf.cstar.ac.com/bf/) and Netbot's Jango (http://www.jango.com) are wellknown examples of such intermediaries. Unfortunately, however, the current Webbased technology makes it very difficult to establish e-brokerage for such searches. Web sites format their CGI requests and HTML outputs in vastly different and often changing ways, each of which must be processed differently. Writing and maintaining a program that keeps track of the various queries and parses the resulting HTML files individually is a cumbersome task [23]. This lack of interoperability standards between e-commerce applications leads to high costs for the e-broker. A second function a broker can support is negotiation. Automated negotiation is poorly supported in current e-procurement systems. Most systems can only support fixed prices; any bargaining must be done person-to-person via e-mail or telephone.

\subsection{Obstacles hindering the Establishment of a Broker Infrastructure}

Current e-procurement systems provide only very limited support for brokerage, partially because of the restrictions of the technology they use. One of the greatest obstacles for the widespread establishment of e-brokers is the lack of interoperability. Without interoperability, procuring from sixty heterogeneous suppliers requires sixty different accommodations. There are no widely adopted interface standards for ecommerce systems. Additionally, HTTP is an inefficient and stateless protocol, which is poorly suited to the multi-step commercial transactions we need in e-commerce [2].

\subsection{Object Frameworks for E-Commerce}

The combination of distributed object computing and the ubiquity of the Internet can serve as a basis for powerful commercial applications. Distributed object standards such as OMG's CORBA provide interoperability of objects across networks in a heterogeneous environment. CORBA supports high-level language bindings, as it separates an interface from its implementation and provides language-neutral data types. It supports polymorphic messaging as well as run-time metadata for describing all interfaces known to the system. So many domain experts claim that an objectoriented architectural framework for Internet commerce will solve many problems of current e-commerce systems [28]. Object frameworks provide collections of cooperating components. They are almost complete applications designed to be reused in a number of applications. In contrast to class libraries, they also define the architecture of the future application. Various examples show the widespread use of this concept [19]. 
There are several research projects developing object frameworks for electronic commerce applications. OMG's Electronic Commerce Domain Task Force (ECDTF) plays a leading role in their standardization. OSM (Open Service Markets) [10], an EU ACTS project, is developing tools to enable an open electronic trading market based on the OMG Object Management Architecture (OMA). A similar approach called eCo was proposed by the CommerceNet consortium [27][28]. ECo is an extensible object-oriented framework based on CORBA and Java. These projects deal with a variety of topics ranging from payment, certificates, and e-catalogs to brokerage.

The current draft of the ECDTF Reference Model [9] gives a good overview of the ongoing efforts. The architecture is composed three principal groups, namely low level electronic commerce services including profile, selection, payment and certificate services; commerce facilities supporting service management, contract and related desktop facilities; and finally, market infrastructure facilities covering catalogue, brokerage and agency facility (see Fig. 1).
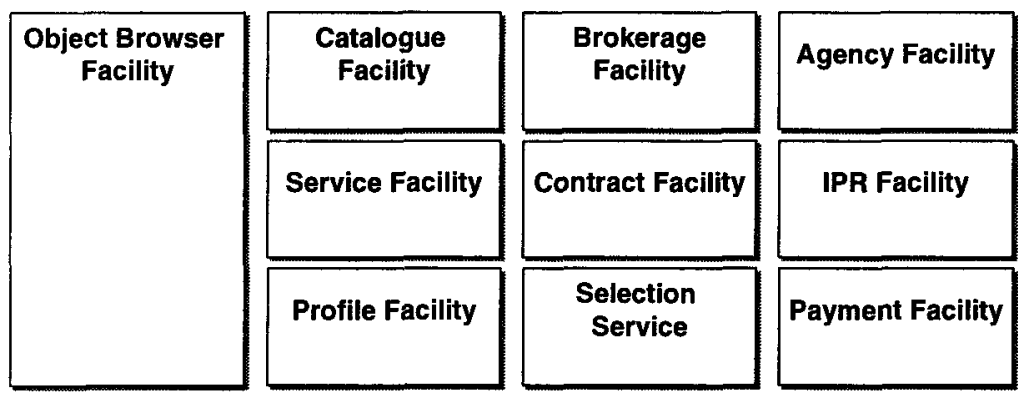

Fig. 1. OMG ECDTF Reference Model

The Reference Model helps to identify the planned and future Electronic Commerce Domain Facilities of the OMG OMA. The work is very promising and provides many ideas, but it is still in its early stages. As of now (February 98) there have been submissions for an Electronic Payment RFP. For a second RFP on a Negotiation Facility, issued in June this year, the responses are still pending. The Brokerage Facility of the ECDTF Reference Model describes only basic interface requirements, namely recruiting and forwarding. These two interfaces correspond to the respective concepts of searching and advertising. In the next section, we describe the services of the electronic broker used in the OFFER framework.

\section{OFFER - A Broker-centered Object Framework}

So far e-brokerage is one of the weak links in e-procurement systems, and we believe a solid broker infrastructure will catalyze the development of many electronic marketspaces for broker-friendly goods. Thus, our work focuses on the establishment of a broker-centered object framework called OFFER. OFFER is a research prototype of a reusable framework for e-procurement. Its main purpose is to obtain deeper 
insight into the architecture of e-procurement frameworks. The project should provide knowledge about the functionality of the required software components, their granularity and the interaction between them.

OFFER is implemented in Java and uses CORBA as a distribution mechanism. The business model consists so far of suppliers, customers and e-brokers. Suppliers and ebrokers offer services which can be accessed over the Internet and which are procured by customers. The interfaces of these services are described in OMG's Interface Definition Language (IDL).

\subsection{Broker-assisted Search in Electronic Catalogs}

This section outlines the workings of a broker-assisted search using the OFFER framework. Suppliers offer an e-catalog to the customer; suppliers can also register with the e-broker. Hence, a customer can search for a service either directly in the ecatalog of a supplier or can use the e-broker to search in all the e-catalogs of all the suppliers, which are registered with this broker. We specify a standard IDL interface for the e-catalogs of a supplier and for the e-broker. Each supplier is responsible for implementing this interface; the implementations can be in any CORBA-compliant language such as $\mathrm{C}++$, Java or Smalltalk. The e-broker IDL provides a search() operation, which allows a customer to find a service with the e-broker and it supports an operation called get SupplierProfiles(), which allows CORBA clients to receive information about the suppliers that are available through the e-broker. Other CORBA services can easily create value-added services on top of those available by the e-broker.

An important requirement is the ability for new e-catalogs to register with the ebroker. The broker can either maintain its own database of registered e-catalogs or it can use the services of an Object Trader. The OMG Trading Object Service became a CORBA standard in mid-1996 [16]. It defines several functional interfaces (Lookup, Register, Link, Admin and Proxy). The Lookup interface, for example, lets the user discover objects based on the properties and services they provide. Via the Register interface one can register (export) or unregister (withdraw) new services with the trader. In our case, the e-catalogs act as exporters, advertising a service offer (consisting of name, location and several other properties) with the trader. The electronic broker acts as an importer, querying a list of references to actually available e-catalogs according to certain constraints. The references can be used afterwards to send a search () message to these electronic catalogs and evaluate the results (see Fig. 2). Some Object Trader implementations provide even the possibility of querying dynamic properties of an exporter at the time a query is made. The advantage of using an object trader is that the e-broker can rely on an already standardized and wellunderstood service for the registration of new e-catalogs. Deployment of an Object Trader is especially useful in environments, where it is already an established service. 


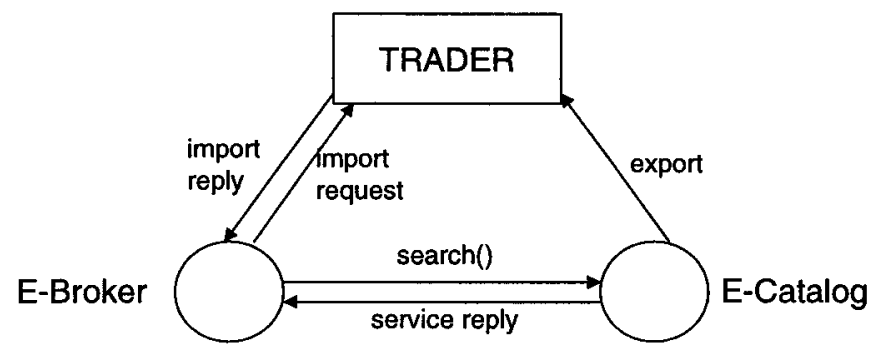

Fig. 2. Deployment of an Object Trader

There are several advantages of using the CORBA-based approach over CGI-based implementations [23]. CORBA 2.0 provides IIOP, an efficient state-supporting protocol on the Internet. As already mentioned, CORBA separates the interface from the implementation. Thus, a CORBA-based e-catalog can change its implementation without requiring the e-broker to rewrite its interface. This is an advantage over current client/server systems, in which the API is often tightly bound to the implementation and therefore very sensitive to changes (see a more detailed discussion in [18]). Nevertheless, also with this CORBA-based approach all suppliers of a certain market have to agree on a predefined interface standard for their ecatalogs, in order to gain high-level interoperability.

\subsection{Broker-assisted Negotiation Support}

An e-broker provides a centralized market place, where many buyers and suppliers can meet. Hence, an e-broker is well situated for offering various kinds of negotiation mechanisms to buyers and sellers. Unfortunately, there do not exist solid bargaining algorithms. Bargaining strategies between a buyer and seller are extremely complex. They frequently evolve over time, and often require shrewd judgements about how much information to reveal, when to lie, how many issues to involve, and which sequence of counterproposals to use. It's a fuzzy science at best [5][20], and efforts to either program strategies into software agents [3], or to have agents learn good strategies [4][15] are not robust enough for commercial applications. Hence, automated negotiation is still in its infancy, in extremely controlled conditions at research laboratories.

In order to achieve solid negotiation support within the OFFER e-broker, we replace the buyer/seller negotiating session with an economic mechanism: the auction. The strategy issue collapses into the single dimension of bid formulation. The software agents can now afford to be "dumb": they need only know the auction rules and submit a bid. In the Vickrey auction, truthtelling is the dominant strategy, and hence optimal bid formulation is extremely simple. For many other auction types, optimal bidding strategies are only slightly more complex. This approach removes the "cleverness" from the software agents and puts it into the market mechanisms instead. In addition to solving the strategy problem, an auction also solves the ontology problem (the item is successfully described at the outset and cannot change during the course of the auction). Table 1 shows the rules, outcomes, and optimal bidder strategies for some major auction formats. Each type of auction has special 
advantages and is suited for special needs. A sealed auction is one in which a prospective bidder doesn't know about his competitors' bids. An open auction is one in which a prospective bidder knows some information (such as price and number of other bidders) about his competitors' bids. For more rigorous discussion, see $[8][11][12][30]$. Because the auction is well suited to electronic commerce applications, there has been a large and relatively immediate commercial success using online auctions to negotiate price between a single seller and several buyers. Auctions on the Internet have been successfully run by Onsale (http://www.onsale.com), eBay (http:/www.ebay.com), Cathay Pacific (http://www.cathaypacific.com), and several other companies [7].

\begin{tabular}{|c|c|c|c|}
\hline Auction & Rules & Outcome & $\begin{array}{l}\text { Optimal Bidder } \\
\text { Strategy }\end{array}$ \\
\hline \multicolumn{4}{|l|}{ Sealed Auctions } \\
\hline $\begin{array}{l}\text { First priced } \\
\text { sealed bid }\end{array}$ & $\begin{array}{l}\text { Bidders submit a } \\
\text { single sealed bid } \\
\text { before deadline }\end{array}$ & $\begin{array}{l}\text { Winner is highest } \\
\text { bid at bid price }\end{array}$ & $\begin{array}{l}\text { Shade bid a bit } \\
\text { below true } \\
\text { willingness to pay }\end{array}$ \\
\hline Vickrey & $\begin{array}{l}\text { Bidders submit a } \\
\text { single sealed bid } \\
\text { before deadline }\end{array}$ & $\begin{array}{l}\text { Winner is highest } \\
\text { bid at second } \\
\text { highest price }\end{array}$ & Truthtelling \\
\hline $\begin{array}{l}\text { Sealed double } \\
\text { auction }\end{array}$ & $\begin{array}{l}\text { Bidders and sellers } \\
\text { submit a single } \\
\text { sealed bid before } \\
\text { deadline }\end{array}$ & $\begin{array}{l}\text { Auctioneer } \\
\text { determines a single } \\
\text { market-clearing } \\
\text { price and matches } \\
\text { buyers and sellers }\end{array}$ & Truthtelling \\
\hline \multicolumn{4}{|l|}{ Open Auctions } \\
\hline Dutch & $\begin{array}{l}\text { Auctioneer calls } \\
\text { out descending } \\
\text { price; bidder calls } \\
\text { out a bid }\end{array}$ & $\begin{array}{l}\text { Winner is first } \\
\text { bidder to call out, } \\
\text { at bid price }\end{array}$ & $\begin{array}{l}\text { Shade bid a bit } \\
\text { below true } \\
\text { willingness to pay }\end{array}$ \\
\hline English & $\begin{array}{l}\text { Bidders } \\
\text { successively raise } \\
\text { bids for item until } \\
\text { single bidder } \\
\text { remains }\end{array}$ & $\begin{array}{l}\text { Winner is last } \\
\text { bidder remaining, } \\
\text { at price of second- } \\
\text { highest bidder }\end{array}$ & $\begin{array}{l}\text { Bid up until true } \\
\text { willingness to } \\
\text { pay, then drop out } \\
\text { of auction } \\
\text { (truthtelling) }\end{array}$ \\
\hline
\end{tabular}

Table 1. Auction Rules, Winners, and Optimal Strategies 


\subsection{Design and Implementation Issues}

For the design of object frameworks it is crucial to identify so-called "hot spots." These are exchangeable components which should guarantee the flexibility of the framework in future applications [19]. Well-designed frameworks provide reusable architectures with flexibility in the right places. As shown above, different auction mechanisms are best suited to different situations. For future applications of the framework it is important to handle these mechanisms flexibly and provide easy extensibility. We achieve this through abstract coupling of the EBroker class with the Auction class (shown in Fig. 3).

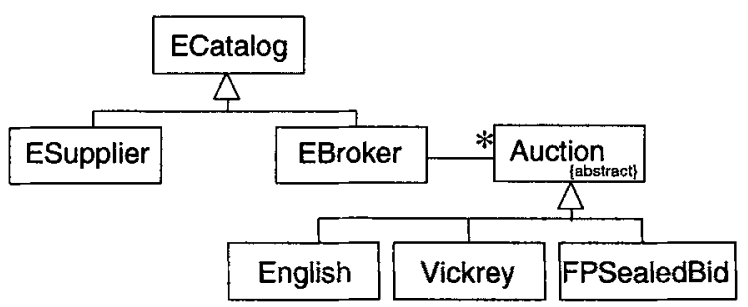

Fig. 3. Abstract Coupling of Classes (UML Class Diagram)

All auctions announce their commencement and the item(s) for sale, as well as a possible reserve price and minimum bid increment. A sealed auction has a publicly announced deadline, and will make no information about the current bids available to any future bidders until the auction is over, at which time the winner(s) is (are) announced. An open auction will make information about current bids available to any future bidders until the auction is over, at which time the winner(s) is (are) announced.

One can open an auction with the e-broker operation startAuction(). Currently this can be either an English, a Vickrey or a First Price Sealed Bid Auction, which are described in Table 1. Through polymorphic messaging, the operations of the appropriate type of auction are triggered afterwards. For example, different auctions, closed via stopAuction() will compute the winners in different manners. Moreover, an English Auction has additional operations like getCurrentBids (), to get a market overview or getElapseTime(), to show how much time is left after the last bid until the auction closes. In our implementation we left out the Dutch auction, as it is strategically equivalent to a First Price Sealed Bid Auction. Currently, anybody can start an auction or participate in an auction. Fig. 4 shows a screenshot of parts of the current user interface. 


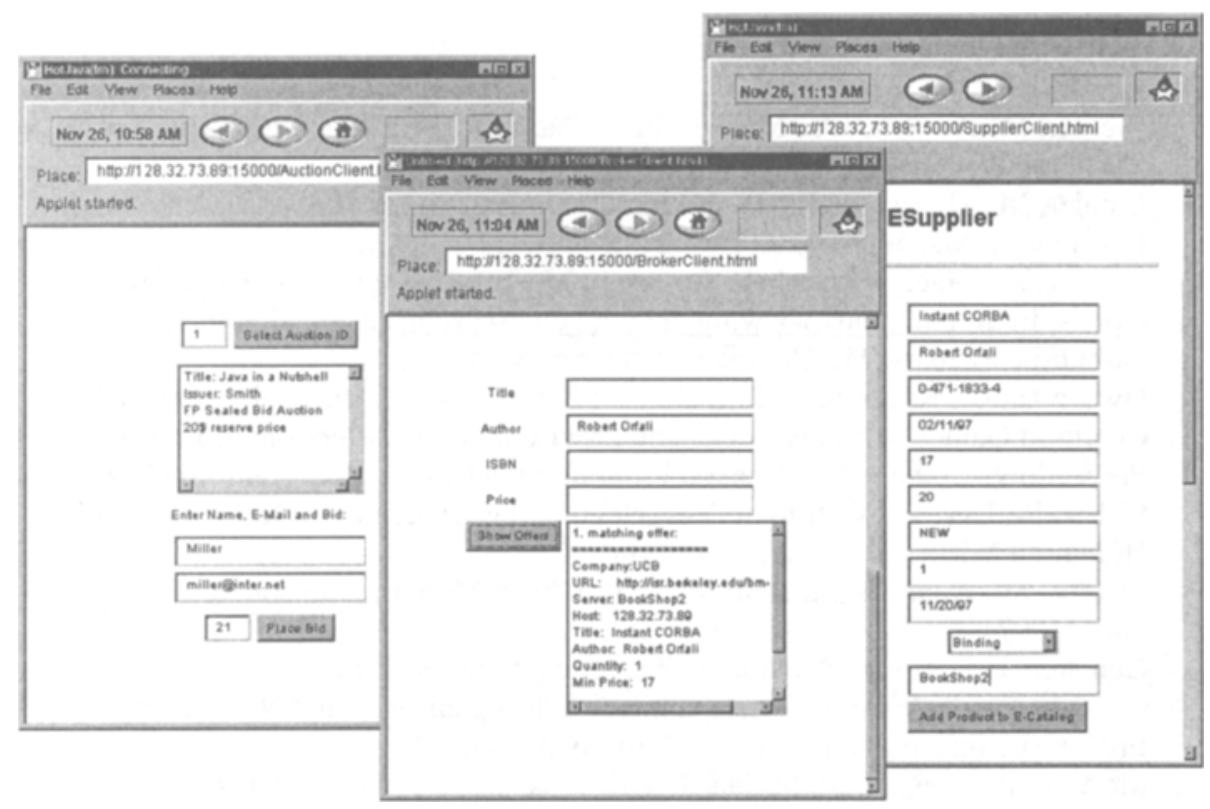

Fig. 4. Screenshot of the e-broker user interface

\section{Conclusions and Future Research}

In this work we propose a flexible architecture for electronic brokers. Moreover, we use auction mechanisms to support multi-party negotiations. There are a few open issues for this prototype. So far, we have only dealt with single item auctions. For reasons of simplicity we only deal with books, which are easy to describe. Matters of security or payment are completely left out of the framework so far. Besides these technical issues, we are also aware of the difficulties in establishing an interface standard, on which all suppliers of a certain product category agree. However, OFFER provides an excellent testbed for new components in an electronic commerce framework.

"Good frameworks are usually the result of many design iterations and a lot of hard work" [31]. Our future research we will address different problems within the area of electronic procurement. We explore the role of electronic notaries in our framework, providing non-repudiation services. We also try to tackle negotiation and contracting in different ways. Technically we are experimenting with component-oriented techniques like JavaBeans in order to make deployment easier. The final goal is to derive design patterns for electronic procurement frameworks [6]. They should be used to describe the architecture of frameworks and make design decisions comparable. 


\section{References}

1. Bichler, M. Freygner, A.: Make or buy - Packaged Software for On-line Shopping Systems. In: iX (1997) 8, 51-55

2. Bichler, M., Hansen, H.R.: Electronic Catalogs on the World Wide Web. In: Information Management 8 (1997), 2-8

3. Chavez, A., Maes, P.: Kasbah: An Agent Marketplace for Buying and Selling Goods. In: http://agents.www.media.mit.edu:80/groups/agents/Publications/ kasbah-paam96.ps: MIT Media Lab (December 1996)

4. Dworman, G., Kimbrough, S., Laing, J.: Bargaining by Artificial Agents in Two Coalition Games: A Study in Genetic Programming for Electronic Commerce. In: Proceedings of the AAAI Genetic Programming Conference, Stanford (1996)

5. Fisher, R., Ury, W.: Getting to Yes: Negotiating Agreement Without Giving In. Houghton Mifflin, Boston, MA (1981)

6. Fowler, M.: Analysis Patterns: Reusable Object Models. Addison Wesley, Menlo Park (1997)

7. Gebauer, J., Hartman, A.: Going once, going twice, sold to the woman with the red sweater - the case of Onsale.com. Virtual-organization.net Newsletter, Institute of Information Systems, Bern, Switzerland 1 (1997)

8. McAfee, R., Preston, McMillan, J.: Auctions and Bidding. In: Journal of Economic Literature. 25 (1987) 699-738

9. McConnell, S.: The OMG/CommerceNet Joint Electronic Commerce Whitepaper. In: http://www.osm.net/about/library.html (December 1997)

10. McConnell, S., Merz, M., Maesano, L., Witthaut, W.: An Open Architecture for Electronic Commerce. OSM OMG/ECDTF/OSM RFI-2 Response (1997)

11. Milgrom, P.: Auctions and Bidding - a Primer. In: Journal of Economic Perspectives 3 (1989) 3-22

12. Milgrom, P. R., Weber, R. J.: A Theory of Auctions and Competitive Bidding. In: Econometrica 50 (1982) 1089-1122

13. Minahan, T.: Chemicals maker puts MRO buys online--finally! In: Purchasing $123(1997)$

14. OBI - Open Buying on the Internet: A Standard for Business-to-Business Internet Commerce. In: http://www.supplyworks.com/obi/white-paper.html (November 1997).

15. Oliver, J. R.: A Machine Learning Approach to Automated Negotiation and Prospects for Electronic Commerce. In: http://opim.wharton.upenn.edu/ oliver27/papers/jmis.ps (December 1996)

16. OMG Negotiation Facility Request for Proposal. In: http://www.omg.org/library/schedule/Negotiation Facility RFP.htm (November 1997)

17. OMG Trading Object Service Specification. In: http://www.omg.org/docs/orbos/96-05-06.ps (November 1997)

18. Orfali, R., Harkey, D.: Client/Server Programming with Java and CORBA. John Wiley and Sons, New York (1997)

19. Pree, W.: Component-based Software Engineering with Frameworks. Dpunkt, Heidelberg (1997)

20. Raiffa, H.: The Art and Science of Negotiation. Harvard University Press, Cambridge (1982) 
21. Schmid, B.: Elektronische Märkte. In: Wirtschaftsinformatik 35 (1993) 465-480.

22. Schmid, B.: Requirements for Electronic Markets Architecture. In: International Journal of Electronic Markets 1 (1997)

23. Schwarzhoff, K.: Apartment Marketplace. In: CommerceNet Research Report \#97-14 (1997)

24. Segev, A., Beam, C., Gebauer, J.: Impact of the Internet on Purchasing Practices. CMIT Working Paper 97-WP-1024, UC Berkeley (1997)

25. Segev, A., Wan, D., Beam, C.: Designing Electronic Catalogs for Business Value: Results from the CommerceNet Pilot. CMIT Working Paper 95-WP-1005, (1995)

26. Sokol, P.: From EDI to electronic commerce: a business initiative. McGraw-Hill, New York (1995)

27. Tenenbaum, J.M., Chowdhry, T.S., Hughes, K.: eCo System: CommerceNet's Architectural Framework for Internet Commerce. CommerceNet Whitepaper (1997)

28. Tenenbaum, J.M., Chowdhry, T.S., Hughes, K.: Eco System: An Internet Commerce Architecture. In: IEEE Computer Journal (1997) 48-55

29. Timbers, P.: Internet Electronic Commerce Business Models. In: http://www.ispo.cec.be/ecommerce/busimod.htm (November 1997)

30. Vickrey, W.: Counterspeculation, Auctions, and Competitive Sealed Tenders. In: Journal of Finance, March (1961) 8-37

31. Wirfs-Brock, R., Johnson, R.: Surveying Current Research in Object-Oriented Design. CACM 33 (1990)

32. Zenz, G., Thompson, G.H.: Purchasing and the Management of Materials, 7 ed. John Wiley and Sons (1994) 8-37 